\title{
Preparing graduate students for graduate-level study and research
}

\author{
Katherine O'Clair \\ Robert E. Kennedy Library, California Polytechnic State University, \\ San Luis Obispo, California, USA
}

\begin{abstract}
Purpose - This paper aims to describe a graduate level course in information research for thesis-based Master's degree students in the College of Agriculture, Food, and Environmental Sciences at California Polytechnic State University for which the College Librarian served as the instructor of record. It also seeks to report the results of research conducted to investigate the impact of the course and its effect on graduate student confidence and preparedness.

Design/methodology/approach - Questionnaires were used to measure student perception of their confidence and preparedness for graduate study and research before and after completing a for-credit course.

Findings - Students' self-perceived levels of confidence and preparedness increased after taking the course. Most felt the course was useful and the content would help them to complete their theses more efficiently and effectively. The majority of students also completed the administrative tasks that are required for graduate-level study.

Originality/value - For-credit, course-based information literacy instruction is common for undergraduates at institutions throughout the US, yet similar offerings for graduate students are rare. Graduate students have specific information needs that require a particular set of skills. A for-credit course designed to meet the needs of graduate students is an effective way to prepare students. Research conducted in conjunction with the offering of this course examines the impact on graduate students' self-perceived confidence and preparedness.
\end{abstract}

Keywords Graduate students, Information literacy instruction, For-credit courses, Academic libraries, Preparation, Students, United States of America, Self esteem

Paper type Case study

\section{Introduction and review of the literature}

Graduate students begin their post-baccalaureate studies with a wide variety of experiences and skill sets, including those associated with information seeking and literature research. Regardless of their prior experience, these students have high level information needs for graduate study and research. This often requires advanced instruction to build the sophisticated set of skills they need to be successful in their coursework and research. Ensuring that graduate students are adequately prepared for these demands is critically important, influencing both retention and the time to achieving a degree, two significant metrics of student and institutional success.

Many thanks to Faye Farmer and Ann Dutton Ewbank for their guidance and direction during the preparation of the manuscript. 
Underprepared graduate students who lack effective information research skills are at a distinct disadvantage, because they may not be able to complete the requirements for their degrees, including the thesis. Students who do not complete their degrees, as well as those who take significantly longer than average are costly to the institution in a number of ways (Harris, 2011). Universities often invest enormous amounts of money, time and energy in their graduate students. Providing graduate students with adequate resources and support, including the library, is required for protecting and increasing return on these investments. Involving a librarian can help to reduce graduate student attrition and improve degree completion rates (Harris, 2011). The first year of graduate study is the best time to establish contact with graduate students to help them become proficient in their information seeking activities (Rempel, 2010). Thus, libraries and academic departments should work in concert to develop these essential skills in their students as early as possible (Conway, 2011).

Graduate students often are poorly prepared for the rigors of graduate-level research and study (Harris, 2011). In a study of undergraduate students after graduation, Conway (2011) found that this group lacked the information literacy skills required for graduate-level study. George et al. (2006) found that graduate students seek and acquire information in a somewhat random fashion, particularly in the early stages of researching a topic. Harrington (2009) studied the graduate research experience and revealed several important perceptions. First, graduate students recognize that their advisors and instructors feel it is important to search the literature comprehensively and cite all relevant articles, yet some of these same students did not find it important themselves. Next, despite the fact that students feel comfortable with the library's physical space, most are apprehensive about seeking assistance from library professionals and prefer to ask advisors, instructors, and peers for help. Only about half felt that formal library instruction would be beneficial (Harrington, 2009). Instead, they often feel compelled to learn from more experienced peers or pursue self-instruction (Rempel, 2010). In addition, graduate students are often unaware of the library's resources and services from which they would benefit (Washington-Hoagland and Clougherty, 2002).

The information needs of graduate students are often overlooked. Academic departments and faculty assume they already have the skills or they will acquire them on their own (Rempel and Davidson, 2008). Moreover, faculty may not have the expertise required to teach the advanced information research skills that most graduate students need (Harris, 2011). Libraries also may overlook the needs of graduate students, because their attention is often focused on teaching undergraduates basic research skills (Monroe-Gulick and Petr, 2012). Graduate students have higher-level information needs and must possess an advanced set of skills, including the ability to comprehensively search the literature, and this requires more advanced instruction than what is provided and necessary at the undergraduate level (Bruce, 1990). Consequently, it is unrealistic to assume that students entering graduate-level programs have the preparation and experience that is required to be successful.

One of the most common obstacles for graduate students is the thesis (Toth, 2005). Several specific challenges may contribute to the failure to complete the thesis in a timely manner. One of the most common reasons is the lack of a clearly defined topic (Rempel, 2010). Establishing an appropriate scope for the topic is equally important, yet students often struggle with this aspect as well (Rempel, 2010). A research topic 
with too broad or too narrow of a scope will turn out to be nearly impossible to manage, and may result in abandonment of the project and failure to complete the degree. Graduate students often do not fully understand the nature and purpose of the literature review, a major component of the thesis (Bruce, 1994). Lack of interaction with the advisor or graduate committee may also hinder progression, as many students rely on the guidance and direction of these individuals as they proceed with the literature review (Rempel, 2010). Many graduate students are unsure of how to conduct the extensive library research that is required, and consequently feel isolated in the process of working on their theses (Bailey, 1985). In addition, students fail to recognize when they should seek input from their advisors and/or graduate committees.

Students who have an understanding of the literature review and who are aware of the literature research resources and tools will be better equipped to proceed through the literature review process efficiently and effectively (Rempel, 2010). Librarians are optimally positioned to facilitate this understanding. They become reliable guides in this process by promoting the library's resources and providing assistance and direction to students along the way (George et al., 2006).

Librarians assist graduate students in determining how to begin and proceed through the literature research process, alleviating the associated anxiety many students experience along the way (Brinkman and Hartsell-Gundy, 2012). In doing this, librarians establish meaningful relationships with those they serve and become a trusted partner, consequently fulfilling the students' affective needs that are commonly overlooked. Brinkman and Hartsell-Gundy (2012) showed that embedding librarians in the graduate programs served to achieve their goals for teaching information literacy, lessened student anxiety, and improved relations with academic departments. Murry et al. (1997) found that nearly all of the education graduate students who completed a course with a faculty-librarian partnership to teach information literacy felt that they had increased their skill level and confidence associated with using the library.

Harrington (2009, p. 186) argues that "the benefits of a research librarian who supports subject-specific, graduate level information literacy and the plethora of services available and supported by a research library needs to be clearly articulated and actively established within the user community". This can be achieved in a variety of ways, including orientations, workshops, and a physical presence in the department. Librarians have the best chance of being successful in their efforts if they meet graduate students at their greatest points of need (Rempel and Davidson, 2008), which usually occurs early, often during the first year of study (Rempel, 2010). Moreover, targeted and tailored services have the highest likelihood of being well-received and ultimately successful (Rempel, 2010). Such proactive efforts will address issues early to enable student success.

Following the widespread and strong focus on information literacy and library instruction for undergraduates, in recent years there has been a growing interest in information literacy instruction for graduate students. A number of efforts have been reported in the literature (Blummer, 2009), including faculty-librarian partnerships (Murry et al., 1997), seminars and workshops (Cunningham and Viola, 2002; Rempel and Davidson, 2008), and for-credit courses (Lowry, 1990; Tag, 2008; Toth, 2005).

Library instruction for graduate students has been shown to increase both skill level and confidence, regardless of the mode of delivery (Shaffer, 2011). Despite this, graduate students tend to prefer face-to-face instruction. Harkins et al. (2011) investigated graduate students' perceptions of two different modes of instruction, an 
online tutorial and an in-class session. They found that the resources and skills taught in the in-class session were highly valued, whereas the online tutorial was grossly underutilized, even as a preparatory exercise for the in-class session.

Workshops specifically targeting the unique needs of graduate students have shown to increase proficiency and help students feel more effective and efficient in their information seeking (Rempel, 2010). Rempel and Davidson (2008) created a series of workshops covering the topics of greatest interest to graduate students, including in-depth instruction on how to use the library's information resources and how to conduct a thorough review of the literature. The demand for these workshops was overwhelming and nearly all those who attended were satisfied with the experience.

For-credit courses for graduate students, although uncommon, are not a new concept. A number of institutions offer for-credit courses and the literature contains several examples of such offerings. The State University of New York Plattsburgh offers a collaboratively taught, for-credit course for the Master of Arts in Liberal Studies degree that teaches basic writing and research skills, introduces the components of the thesis, and helps students develop their topics and research questions (Toth, 2005). In addition, Western Washington University requires a course in library and information research for graduate and professional students in the Master of Arts in Communication Sciences and Disorders degree program, which students take at the start of their graduate study (Tag, 2008). For-credit courses teach students important skills. Students who completed a for-credit course in library research demonstrated a higher level of proficiency and retained this information after completing the course (Wang, 2006).

\section{Institutional context}

California Polytechnic State University (hereafter, Cal Poly) is part of the California State University system and is located in San Luis Obispo, California. It is a comprehensive polytechnic institution offering 68 bachelor's degree and 29 master's degree programs (California Polytechnic State University, n.d.). In 2011, student enrollment included 17,725 undergraduate students and 919 graduate students (California Polytechnic State University, 2011). The College of Agriculture, Food and Environmental Sciences (hereafter, College) offers three Master of Science degrees including Agribusiness, Agriculture, and Forestry Sciences. Students in the MS Agriculture degree program select one of the following specializations (California Polytechnic State University, 2012):

- agricultural engineering technology;

- animal science;

- crop science;

- dairy products technology;

- environmental horticultural science;

- food science and nutrition;

- irrigation;

- plant protection science;

- recreation, parks and tourism management; and

- soil science. 
The College enrolled 30 new students in fall 2011, bringing the total graduate enrollment in the College to 94 students (California Polytechnic State University, 2011). Graduate students pursuing a Master of Science degree must complete 45 units of graduate-level coursework approved by the student's graduate committee as part of the formal study plan, as well as a thesis based on original and independent research (California Polytechnic State University, 2012).

\section{Description of the course}

There was a strong demand for more graduate level courses in the College, and particularly for a course to familiarize new graduate students with the literature research resources available to them. In addition, the College was seeking interventions to ameliorate the lengthy average time to degree (3.8 years). The course was designed and developed to equip graduate students with advanced information research and management and also to motivate them to start their thesis research during the first term of graduate study. Its purpose was to provide instruction on using information resources, organizing and managing research, and identifying and developing a meaningful research topic. Students were required to address specific administrative tasks, which historically have been neglected by new graduate students during the first term in the graduate program. These included creating their formal study plans, identifying members for their graduate committees, and meeting regularly with their advisors to discuss both coursework and thesis research. Although this is beyond the librarian's scope and role, completion of these administrative tasks is critical to student success and timely progress to degree, so it was prudent to include them as part of the curriculum of this course. Students completed these tasks outside of class, so their inclusion did not impede any of the information literacy instruction.

The course was first offered during the fall 2011 quarter as a 1-credit hour section of AG 598 - Reading and Conference. The class met face-to-face for 50 minutes once a week (11-week quarter) in a library computer lab, which allowed the students to engage in hands-on learning of the material. The College Librarian was responsible for designing the course's curriculum, delivering the instruction, and assessing student learning and progress. The College Librarian worked closely with the College on the logistics of the course, including scheduling the course, recruiting students, and ensuring the course content was not duplicated in other graduate-level courses. Enrollment was limited to 24 students, and new thesis-based graduate students were strongly encouraged, but not required, to take the course. Although the course was intended for new students in the first quarter of graduate study, all graduate students in the College were permitted to enroll as a result of the strong interest and demand for the course by returning students and their advisors.

The course had three broadly defined themes: topic selection; literature resources and search strategies; and research management and organization. The learning objectives for the course included the ability to: discuss the thesis topic; identify the tools used to gather information for the literature review; apply search strategies for efficient retrieval of information in databases, catalogs, and search engines; use EndNote Web to organize research; and construct citations in proper format in a style most appropriate for the student's discipline. In addition, the following administrative were incorporated into the course: establish the graduate committee; meet regularly with the advisor (who serves as the graduate committee chair); and complete the formal study plan. 
The course included a variety of assignments appropriate for a 1-credit course that facilitated early initiation of the thesis research. Grading for the course was credit/no credit (all sections of AG 598 are graded similarly), and students were required to achieve 80 percent or higher to receive credit for the course. The two major assignments for this course were the Research Topic Bibliography (20 percent of the final grade), a list of ten references in proper format (in a style relevant to the discipline) related to the thesis research topic and the Research Plan Presentation (15 percent of the final grade), a 5-7 minute in-class presentation on their thesis research topics, graduate committee members, and short- and long-term plans. Additional assignments included research interest and thesis topic statements, a mid-term progress report, records of meetings with advisors, completed forms for the formal plan of study and graduate committee membership, and in-class participation.

\section{Methodology}

This research aims to answer the following question: Does a for-credit course for graduate students have an impact on their self-perceived levels of confidence and preparedness for thesis-based literature research? Students enrolled in AG 598 during the fall 2011 quarter were asked to complete online questionnaires (via SurveyMonkey) at the beginning and the end of the course. The research and data collection protocols were approved by the Cal Poly Office of Research and Graduate Programs, and students had the option to decline participation. All responses were anonymous.

The first questionnaire was administered during the second week of the academic quarter, after the introduction to the course in the first week, but before delivery of curricular content. The questionnaire included questions about educational experience, previous use of the library and its resources, and self-perceived levels of confidence and preparation for thesis-based literature research. It also asked students to state whether they had previously met with their advisors, formed their graduate committees, and completed their formal study plans. The same confidence, preparedness and administrative questions were asked again in the second questionnaire, which was administered at the end of the course during the last week of the quarter. In addition, the students were asked to identify aspects of the course they found to be useful, suggestions for improvement, whether the course met their expectations, and if they felt the course would help them to complete the thesis more efficiently and effectively. The questionnaire also asked students if the course was a valuable use of their time; if they would recommend it to their peers; and if they thought it should be a required part of the graduate curriculum.

\section{Findings}

First questionnaire

The 23 students enrolled in the course during fall 2011 completed the questionnaire. The majority of these students $(n=21)$ were formally matriculated in the university's graduate program, and the remaining two students were enrolled through Cal Poly Continuing Education and intended to matriculate the following quarter (Winter 2012). Returning students comprised the majority of respondents (65.2 percent), while new students made up just 34.8 percent. Half had completed their undergraduate degrees at Cal Poly, and only one student had achieved an advanced degree prior to beginning graduate study at Cal Poly. All reported previously using the library at least once a 
month, but consultation with a librarian occurred far less frequently, if at all (Figure 1). Many (60.9 percent) had attended at least one library instruction session prior to the course, either at Cal Poly or at another institution. Google Scholar (73.9 percent) and Web of Science (52.2 percent) were the most commonly used databases, and two reported no prior use of article databases. Only 39.1 percent had previous experience using a bibliographic research management tool (e.g. EndNote, RefWorks).

More than half of the respondents claimed to have a clearly defined research topic (60.9 percent), felt confident in researching the literature (72.2 percent), and were comfortable using databases to search for articles (56.5 percent) (Figure 2). Very few reported having an effective way to organize and manage their research (17.4 percent), and even fewer felt prepared to write the literature review (13.0 percent), despite the fact that nearly half stated they knew what was involved in the process (43.5 percent) (Figure 2). For the administrative tasks, the majority had met with their advisors (87.0 percent), but far fewer had formed their graduate committees (34.8 percent) and completed their formal study plans (26.1 percent) (Figure 3).

\section{Second questionnaire}

Fewer students $(n=18)$ completed the second questionnaire administered at the end of the course (the other five students enrolled in the course chose not to participate for reasons which are not known. The average overall rating for the course was 7.4, on a scale of 0 to 10, (10 being the highest). Students stated that the most useful things they learned were how to use the databases to search for articles and how to use EndNote Web to organize and manage literature research. Many expressed a desire for more

Figure 1.

Previous library experience of students in the course

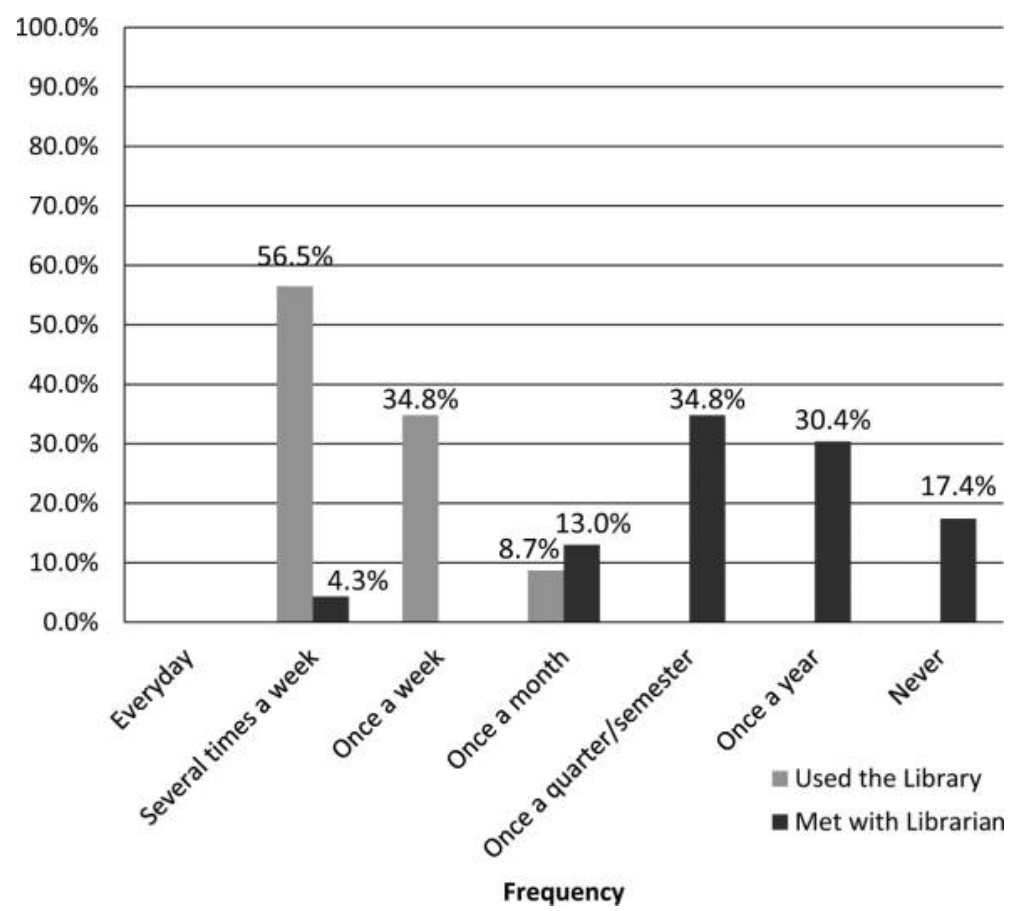



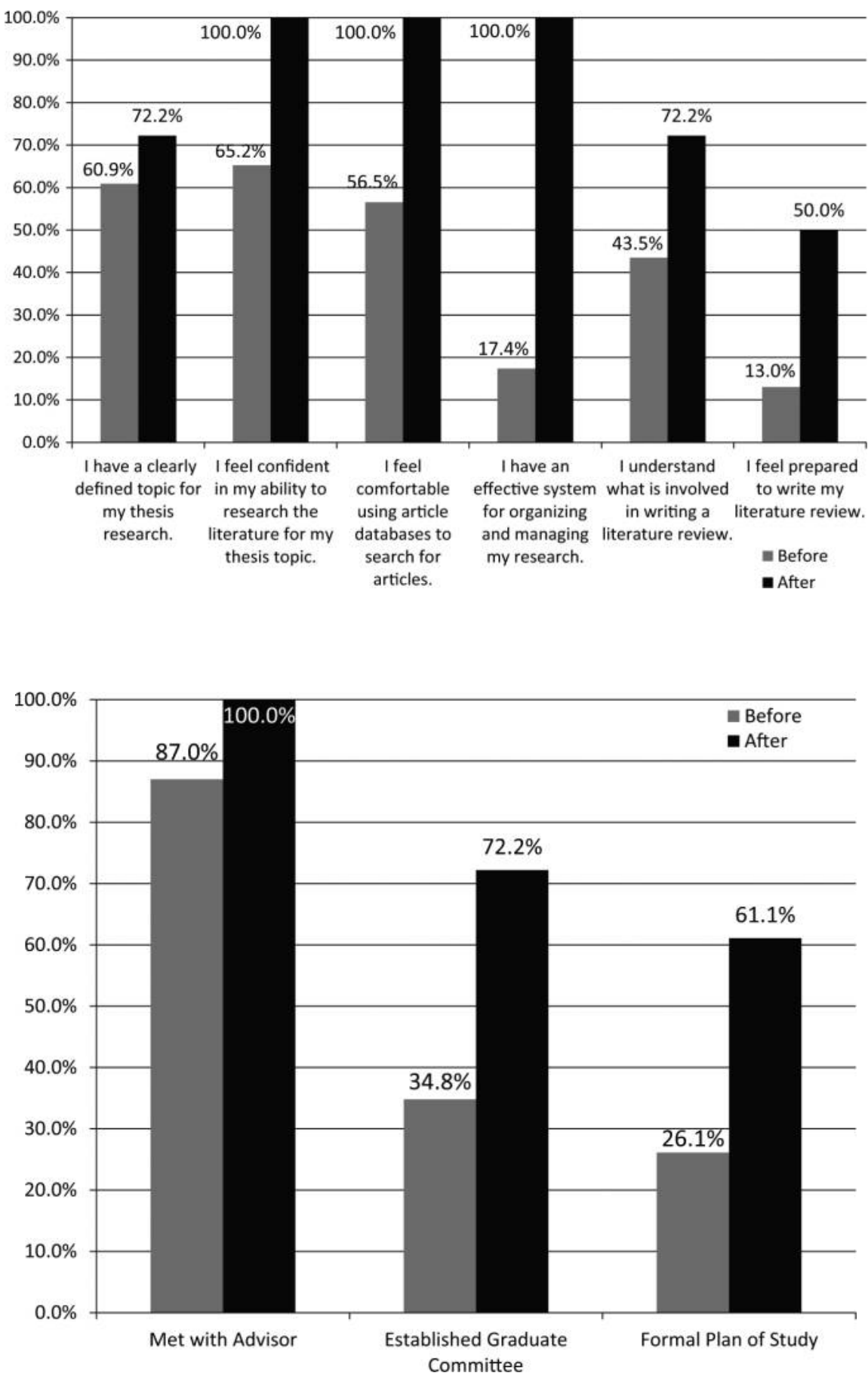

Figure 2.

Self-perceived levels of preparedness and confidence with thesis research and associated tasks before and after completing the course
Figure 3.

Completion of administrative tasks by students before and after com 
Figure 4.

Student ratings of the course time in class (i.e. meeting more than once per week) and more time for hands-on work during the class. The majority of students felt that the course was both useful $(83.3$ percent) and valuable (77.8 percent) (Figure 4). Most also felt that the course was a good use of time (72.2 percent) and would recommend the course to other graduate students (72.2 percent), yet only slightly more than half thought the course should be required for all new graduate students (55.6 percent) (Figure 4). Over 75 percent of the students reported that the course met their expectations (Figure 5) and that it would help them to complete the thesis more efficiently and effectively (Figure 6).

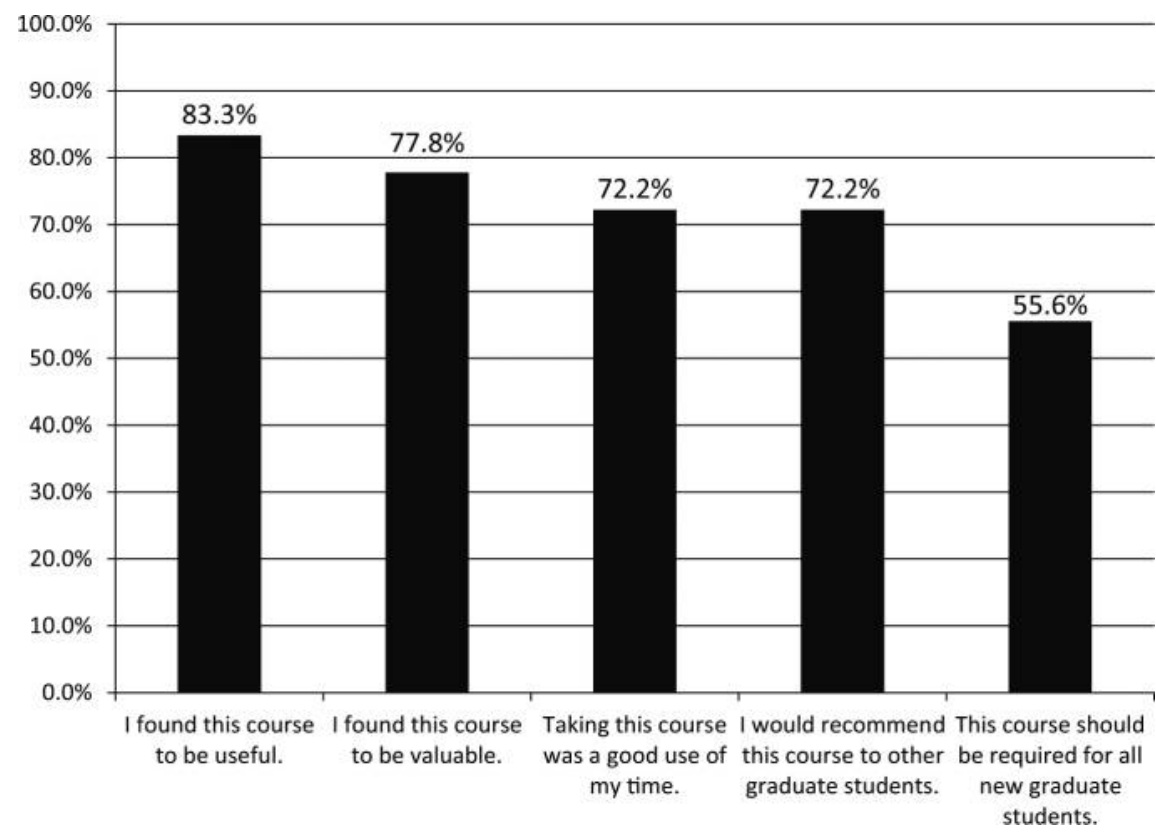

Figure 5.

Student expectations of the course

\section{Did this course meet your expectations of what you wanted to learn?}

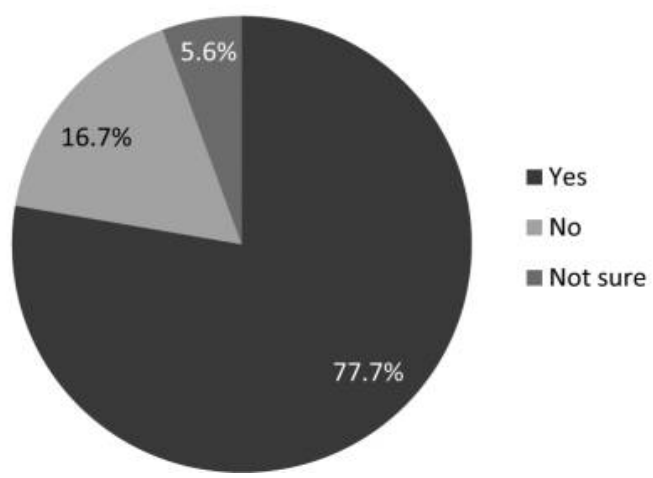




\section{Do you think this course will help you to complete your Master's Thesis more efficiently and effectively?}

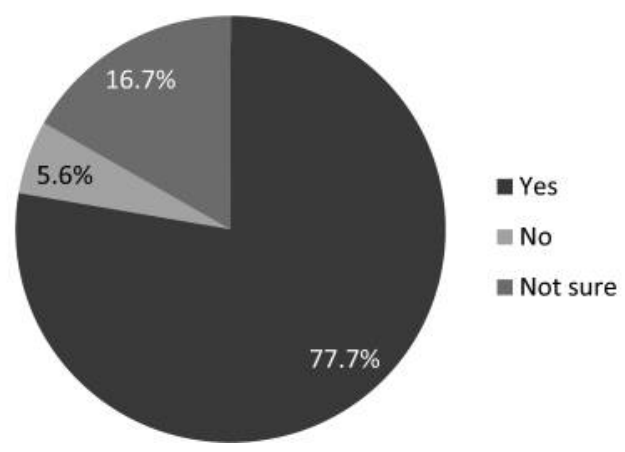

Figure 6. Student perceptions of the course

The reported levels of preparedness and confidence increased in all areas (Figure 2). Nearly 75 percent stated they had a clearly defined topic by the end of the course. All respondents indicated that they felt confident in their ability to research the literature, comfortable using appropriate databases, and effective in organizing and managing their research after taking the course. There was an increase in the understanding of what is involved in writing a literature review (72.2 percent), yet only 50 percent felt that they were prepared to write the literature review after taking the course. There was also an increase in the completion of the administrative tasks associated with the course (Figure 3). By the end of the course all students had met with their advisors, and the majority had established their graduate committees (72.2 percent), but only slightly more than half had completed their formal study plans (61.1 percent).

\section{Discussion}

The data show that students reported higher levels of self-perceived confidence and preparedness after taking this course. They also felt that the course was useful and what they learned would help them to complete the thesis more efficiently and effectively. Comments from students, two in particular, show that the course is considered to be worthwhile and useful for graduate students:

This course should be required of all graduate students. It provides outstanding coverage of library resources and access to research materials.

I feel 100 percent more confident in my thesis project and research abilities now that I have taken this course.

\section{Limitations}

The small sample size limits the statistical analysis of the data and makes it difficult to say that a for-credit course is the best way to prepared graduate students for graduate level study and research. All data was collected in aggregate, so before and after responses cannot be linked at an individual level. In addition, not all students completed the second questionnaire. Reasons for this were not captured, but the lack of 
these responses may have skewed the results. Despite these limitations, it is still possible to draw a few meaningful conclusions from this study in regards to information literacy and early intervention for graduate students.

\section{Timely progress to degree}

The data support the assertion that some graduate students at Cal Poly were slow to get started on their thesis research, a trend that Rempel (2010) also observed in her study of graduate students at Oregon State University. The data show that many students did not complete the required administrative tasks during their first year of graduate study. Returning students do not feel prepared and confident, even after a year of graduate study. While not directly assessed, this may be a consequence of a lack of information research skills. Moreover, the data show that they have not completed some of the important administrative tasks they are responsible for as graduate students. Completion of these tasks during the first quarter of study is imperative for timely progress to degree. This, along with the lack of confidence and preparedness, makes a strong case for the need for an intervention as early as possible to help graduate students get on track and stay on track. Such an intervention may also help to reduce the time to degree, an issue that already is a concern for graduate students in the College.

\section{Clearly defined topics}

The majority of students reported having a clearly defined topic at the beginning of the course. Many (65.2 percent) were returning students, and it is not surprising that most of these students have clearly defined topics by this time. In fact, 73.3 percent of the returning students had clearly defined topics, yet there were four individuals who stated they did not have clearly defined topics even after a year of graduate study. This is alarming, and the limitations in the data collection make it impossible to know if this situation was resolved while taking the course.

There was only a small increase in the percentage of students who had clearly defined topics at the end of course relative to the beginning. This is of concern, because nearly a quarter of the students still did not have clearly defined topics after a course that required several activities in support of this. It is possible that some students thought they had clearly defined topics at the beginning of the course when, in fact, they did not, or they may have changed or modified their topics during the quarter and still felt unsure.

\section{Literature searching}

Most students reported feeling confident in their ability to research the literature before the course, yet of the new students, only 25 percent reported feeling this way. After the course, this confidence increased to 100 percent for both new and returning students. A similar trend is seen in their comfort level using databases to search for articles (i.e. 100 percent of students reported a high degree of comfort by the end of the course). The results from the first questionnaire were expected when considering the high number of returning students in the class, and clearly this course helped to improve levels of confidence and comfort with literature searching in both new and returning students. 


\section{Literature organization and management}

Only four students reported having an effective way to organize and manage their research in the first questionnaire and all of these were returning students. This increased to 100 percent by the end of the course, but it is alarming that so many returning students had not identified and developed a strategy after a year of graduate study. This was one of the primary learning objectives for the course, and it is likely that without this course, this number would still be very low.

\section{The literature review}

Although there was an increase in the before and after responses for understanding what is involved in writing the literature review and feeling prepared to do so, the data show that some students are still struggling in these areas. Even after the course, more than 25 percent of the students still did not fully understand the process for writing the literature review, and only 50 percent felt prepared to write the literature review. This is troubling, because many of these students go on to take a required course in the following quarter in which they are required to complete the literature review. Two students expressed that they thought this was one of the areas in which this course could be improved:

I did not learn how to specifically put together my literature review. I thought that should have been covered in more detail using our own articles that we had gathered.

I would like to learn more about doing a literature review.

Clearly, students need more guidance and direction in this area, so the course content should be adapted to address the lack of confidence and preparedness in this area.

\section{Administrative tasks}

The rates of completion of the administrative tasks associate with graduate study improved by the end of this course, but there is still some cause for concern. Nearly all students had met with their advisors at the beginning of the course, and 100 percent had done so by the end of the quarter. There was a noticeable increase in the before and after results for establishing the graduate committee and completing the formal study plan. Despite this, a number of students still had not completed these tasks, all of which were requirements of the course.

The before responses of the returning students are the most surprising. One returning student had not yet met with his or her advisor, and most students still had not established their graduate committees or completed their formal study plans $(60.0$ percent and 66.7 percent, respectively). Although most students had met with their advisors, the data reveal a lack of engagement with the advisor in completing these other important tasks. A lack of engagement to complete these formal, required tasks may speak to a greater problem of lack of engagement with the advisor on issues and concerns related to the thesis research, and both of these may delay progress to degree.

\section{Future course offerings}

This course was offered in fall 2012 with modifications based the observations of the instructor and feedback from the students, gathered in the second questionnaire and as part of the College's formal course evaluations. Importantly, because of the initial success of the course and the feedback gathered from students in the fall 2011 offering, 
it was expanded to a 2-credit course that met twice weekly for 50 minutes. The content was expanded only slightly, providing additional time to delve into specific content and allow students to explore the application what they had learned, thus reflecting the top two recommendations of fall 2011 students.

\section{Future research}

To build on the preliminary data that was collected for this research study, additional data was collected during the fall 2012 offering of the course. The same questions were included on the questionnaires, but anonymous self-generated identification codes were used to track the responses of individual students. The long-term impacts of this course should also be investigated to see if this course plays a role in reducing the time to degree. Because the course is not required, not all students choose to take it. The differences in time to degree could be compared between those students who take the course and those who do not to determine if this course helps students complete their graduate study and theses in a timely manner. This will test the assumption that students who participate in graduate-level information literacy instruction early in their graduate studies will make progress to degree in a shorter amount of time than those who do not. Certainly, other factors will impact the time to degree, but it is worth investigating the role such a course may play in preparing students for the graduate-level study and research.

\section{Conclusion}

Graduate students often do not possess the advanced set of information research skills they will need to be successful in their coursework and research, despite previous exposure to the library's resources and services, including instruction. A for-credit course, such as the one described in this paper, is one of the ways that librarians can support the high-level needs of graduate students and contribute to their long-term success. The results of the research reported here shows that the majority of students who completed a for-credit course found it both valuable and useful. In addition, participation in the course helped to increase the levels of confidence and preparedness in graduate students engaged in thesis research. For-credit courses can serve as an important intervention to prepare new graduate students for their studies and research and increase the likelihood of successful and timely completion of their degrees.

\section{References}

Bailey, B. (1985), “Thesis practicum and the librarian's role”, Lournal of Academic Librarianship, Vol. 11 No. 2, pp. 79-81.

Blummer, B. (2009), "Providing library instruction to graduate students: a review of the literature", Public Services Quarterlv, Vol. 5 No. 1, pp. 15-39.

Brinkman, S.N. and Hartsell-Gundy, A.A. (2012), "Building trust to relieve graduate student research anxiety”, Public Services Quarterlv, Vol. 8 No. 1, pp. 26-39.

Bruce, C.S. (1990), "Information skills coursework for postgraduate students: investigation and response at the Queensland University of Technology", Australian Academic and Research Libraries, Vol. 21 No. 4, pp. 224-232.

Bruce, C.S. (1994), "Research students' early experiences of the dissertation literature review", Studies in Higher Education, Vol. 19 No. 2, pp. 217-229. 
California Polytechnic State University (n.d.), "Cal Poly quick facts", available at http:// calpolynews.calpoly.edu/quickfacts.html (accessed 12 June 2012).

California Polytechnic State University (2011), “Cal Poly fall 2011 fact book”, available at: www. ipa.calpoly.edu/sites/ipa.wcms.calpoly.edu/files/publications_reports/factbook/fbfall11. pdf (accessed 12 June 2012).

California Polytechnic State University (2012), “2011-2013 Cal Poly catalog”, available at: http:// catalog.calpoly.edu/ (accessed 12 June 2012).

Conway, K. (2011), "How prepared are students for postgraduate study? A comparison of the information literacy skills of commencing undergraduate and postgraduate information studies students at Curtin University", Australian Academic \& Research Libraries, Vol. 42 No. 2, pp. 121-135.

Cunningham, D. and Viola, D. (2002), "Collaboration to teach graduate students how to write more effective theses", Iournal of the Medical Library Association, Vol. 90 No. 3, pp. 331-334.

George, C., Bright, A., Hurlbert, T. and Linke, E.C. (2006), "Scholarly use of information: graduate students' information seeking behavior", Information Research, Vol. 11 No. 4, available at: http://InformationR.net/ir/11-4/paper272.html (accessed 14 June 2012).

Harkins, M.J., Rodrigues, D.B. and Orlov, S. (2011), ), "Where to start?': considerations for faculty and librarians in delivering information literacy instruction for graduate students", Practical Academic Librarianship: The International Journal of the SLA Academic Division, Vol. 1 No. 1, pp. 28-50, available at: http://journals.tdl.org/pal/article/viewFile/1463/1852 (accessed 14 June 2012).

Harrington, M.R. (2009), "Information literacy and research-intensive graduate students: enhancing the role of research librarians", Behavioral \& Social Sciences Librarian, Vol. 28 No. 4, pp. 179-201.

Harris, C.S. (2011), "The case for partnering doctoral students with librarians: a synthesis of the literatures", Librarv Review, Vol. 60 No. 7, pp. 599-620.

Lowry, A.K. (1990), "Beyond BI: information literacy in the electronic age", Research Strategies, Vol. 8 No. 1, pp. 22-27.

Monroe-Gulick, A. and Petr, J. (2012), "Incoming graduate students in the social sciences: how much do they really know about library research?", Portal: Libraries and the Academv, Vol. 12 No. 3, pp. 315-335.

Murry, J.W., McKee, E.C. and Hammons, J.O. (1997), "Faculty and librarian collaboration: the road to information literacy for graduate students", Journal on Excellence in College Teaching, Vol. 8 No. 2, pp. 107-121.

Rempel, H.G. (2010), "A longitudinal assessment of graduate student research behavior and the impact of attending a library literature review workshop", College \& Research Libraries, Vol. 71 No. 6, pp. 532-547.

Rempel, H.G. and Davidson, J. (2008), ), "Providing information literacy instruction to graduate students through literature review workshops", Issues in Science and Technology Librarianship, Vol. 53, available at www.istl.org/08-winter/refereed2.html (accessed 14 June 2012).

Shaffer, B.A. (2011), "Graduate student library research skills: is online instruction effective?", Journal of Library \& Information Services in Distance Learning, Vol. 5 Nos 1-2, pp. 35-55.

Tag, S.G. (2008), "A library research course for graduate and professional students in communication sciences and disorders", Public Services Quarterly, Vol. 3 Nos 3-4, pp. 115-139. 
Toth, M. (2005), "Research and writing and theses-oh my! The journey of a collaboratively taught graduate research and writing course", The Reference Librarian, Vol. 43 Nos 89-90, pp. 81-92.

Wang, R. (2006), "The lasting impact of a library credit course", Portal: Libraries and the Academv, Vol. 6 No. 1, pp. 79-92.

Washington-Hoagland, C. and Clougherty, L. (2002), "Identifying the resource and service needs of graduate and professional students: the University of Iowa user needs of graduate professional series", Portal: Libraries and the Academv, Vol. 2 No. 1, pp. 125-143.

\begin{abstract}
About the author
Katherine O'Clair is the College Librarian for the College of Agriculture, Food and Environmental Sciences at California Polytechnic State University in San Luis Obispo. Her professional interests include the integration of information literacy into the curriculum and early career issues in librarianship. Katherine O'Clair can be contacted at: koclair@calpoly.edu
\end{abstract}

